\title{
Dynamics of total extracellular water of the body during the modification of ultrafiltration after artificial circulation
}

\author{
Nurlan Bayzhigitov ${ }^{1}$, Vitali Pak ${ }^{2}$, Tolegen Egemberdiev ${ }^{1}$, Taimaz Tleuberlin ${ }^{1}$
}

${ }^{I}$ Department of Cardiovascular Surgery, S.D. Asfendiyarov Kazakh National Medical University, Almaty, Republic of Kazakhstan

${ }^{2}$ Cardiology Department, G. Monasterio Foundation Hospital, Massa, Italy

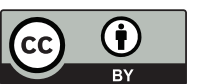

This work is licensed under a Creative Commons Attribution 4.0 International License

Received: 2018-03-29

Accepted: 2018-10-15

UDC: 616.1

J Clin Med Kaz 2018;3(49):42-45

Corresponding Author: Taimaz Tleuberlin, Department of Cardiovascular Surgery, S.D. Asfendiyarov

Kazakh National Medical University. Address: 10-7, Kashgarskaya Street, Almaty, Republic of Kazakhstan. Tel.: 87472021688

E-mail: taimaztleuberlin@gmail.com
Abstract

Aim: This article aims to investigate the dynamics of the total extracellular water of the body when performing modified ultrafiltration after artificial circulation.

Methods: 50 patients were examined, from 1 to 8 years. Half of them - with congenital heart defects (the main group) under conditions of modified ultrafiltration of blood after artificial circulation, the other - a control group of children operated under conditions of artificial circulation, without performing a modified ultrafiltration of blood.

Results: In the course of the study, the authors presented the drawings showing their own scheme for carrying out the modified ultrafiltration, the effect of modified ultrafiltration on the perioperative changes in the total extracellular water of the body in the control and main groups, as well as the perioperative dynamics of total extracellular water in $45 \%$ of the children in the main group. Particular attention is drawn to Table 1, which presents the numerical values of bioelectroimpedance determined in the study groups at different stages of the operation and in the postoperative period, and an assessment of its dynamic changes is given.

Conclusion: The obtained results of the studies allow us to recommend a method of modified ultrafiltration of blood for correction of water metabolism disorders in children during heart operations with artificial circulation. In the conclusions, data analysis showed that carrying out artificial circulation promotes the accumulation of fluid in the extracellular extravascular space (an average of $25.8 \pm 2.7 \%$ ). Conducting a modified ultrafiltration of blood after an artificial circulation helps to prevent the accumulation of fluid in the extravasal space.

Key words: modified ultrafiltration, artificial circulation, bioelectroimpedance, total extracellular water of the body, congenital heart defects

ЖАСАНДЫ ҚАН АЙНАЛЫМЫНАН КЕЙІН ТҮРЛЕНДІРІЛГЕН УЛЬТРАСУЗУ КЕЗІНДЕ ЖАЛПЫ ЖАСУША ІШІЛІК СУДЫН ДИНАМИКАСЫ

Байжигитов Н.Б. ${ }^{1}$, Пак В. ${ }^{2}$, Егембердиев Т.Ж. ${ }^{1}$, Тлеуберлин Т.К. ${ }^{1}$

'Жүрек-қан тамырлары хирургия бөлімі, С.Д.Асфендияров атындағы Қазақ Ұлттық Медицина Университеті, Алматы, Қазақстан Республикасы

${ }^{2}$ Кардиология бөлімі, Г. Монастерио ауруханасы, Масса, Италия

\section{ТҰЖЫРЫМДАМА}

Мақсаты: Осы мақаланың мақсаты ретінде жасанды қан айналымынан кейін түрлендірілген ультрасүзу кезінде жалпы жасуша ішілік судың динамикасын зерттеу болып табылады.

Әдістері: Бақылауға 1 мен 8 жас аралығындағы 50 пациент алынды. Олардың жартысы - туа біткен жүрек ақауымен (негізгі тобы) жасанды қан айналымынан кейін түрлендірілген ультрасүзу өткізу жағдайларында, екіншісі - түрлендірілген ультрасүзусыз жасанды қан айналымысыз талаптарда операция жасалған балалардың бақылау тобы. Олардың барлығы 2016 жылдан 2017 жылға дейін Масса қаласында, Италия елінде Монастерио ауруханасы Кардиология бөлімінде ем алған.

Нәтижелері: Зерттеу барысыныда авторлармен келесі суреттер ұсынылған: түрлендірілген ультрасүзу өткізудің жеке кестесі, бақылау және негізгі топтарда организмдердегі жалпы жасуша ішілік судың операциядан кейін өзгерістерге түрлендірілген ультрасүзілудің әсері, сонымен қатар негізгі топтағы 45\% балалар организмдеріндегі жасуша ішілік судың операциядан кейінгі динамикасы. Негізгі назар 1 кестеге қойылады, онда операцияның түрлі кезеңдерінде және операциядан кейін кезеңде зерттелетін биоэлектроимпеданстың цифрлы мағынасы ұсынылған және оның динамикалық өзгерісіне баға берілген.

Қорытындылары: Зерттеулерден алынған нәтижелер жасанды қан айналымындағы жүрекке операция жасау кезінде балаларда су 
айналымы бұзылғанын түзету үшін қанды түрлендірілген ультрасүзу әдісін ұсынуға мүмкіндік береді. Мәліметтер талдамасының тұжырымы жасанды қан айналымын өткізу жасуша ішілік сыртқы түтіктік кеңістікте сұйықтық жиналуға алып келетінің көрсетті (орташа есеппен 25,8 2,7\%). Жасанды қан айналымынан кейін қанның түрлендірілген ультрасүзілуін жүргізу экстравазальды кеңістікте сұйықтықтың жиналуының алдын алуға жәрдем етеді. Және барлық балаларда жасуша сыртында сыртқы жасушалық кеңістікте судың төмендеуі бойынша түрлендірілген ультрасүзілу әдісі айрықша көрініп тұр.

Негізгі сөздер: түрлендірілген ультрасүзілу, жасанды қан айналымы, биоэлектроимпеданс, организмнің жалпы жасушалық су, туа біткен жүрек ақауы

\section{ДИНАМИКА ОБЩЕЙ ВНЕКЛЕТОЧНОЙ ВОДЫ ОРГАНИЗМА ПРИ ПРОВЕДЕНИИ МОДИФИЦИРОВАННОЙ УЛЬТРАФИЛЬТРАЦИИ ПОСЛЕ ИСКУССТВЕННОГО КРОВООБРАЩЕНИЯ}

Байжигитов Н.Б. ${ }^{1}$, Пак В. ${ }^{2}$, Егембердиев Т.Ж. ${ }^{1}$, Тлеуберлин Т.К. ${ }^{1}$

${ }^{1}$ Кафедра сердечно-сосудистой хирургии, Казахский Национальный Медицинский университет им. С.Д. Асфендиярова, Алматы, Республика Казахстан

${ }^{2}$ Отделение кардиологии, Больница Г. Монастерио, Масса, Италия

\section{PEЗЮME}

Цель: В данной статье ставится цель исследовать динамику общей внеклеточной воды организма при проведении модифицированной ультрафильтрации после искусственного кровообращения.

Методы: Под наблюдение взяты 50 пациентов, от 1 до 8 лет. Половина из них - с врожденными пороками сердца (основная группа) в условиях проведения модифицированной ультрафильтрации крови после искусственного кровообращения, другая - контрольная группа детей, оперированных в условиях искусственного кровообращения, без проведения модифицированной ультрафильтрации крови. Все они находились на лечении в отделении детской кардиохирургии, Больница Г. Монастерио, г.Масса, Италия в период с 2016 по 2017 гг.

Результаты: В ходе исследования авторами представлены рисунки, где отображены: собственная схема проведения модифицированной ультрафильтрации, влияние модифицированной ультрафильтрации на периоперационные изменения общей внеклеточной воды организма в контрольной и основной группах, также периоперационная динамика общей внеклеточной воды организма у 45\% детей основной группы. Особое значение обращается на Таблицу 1, в которой представлены цифровые значения биоэлектроимпеданса, определенные в исследуемых группах на разных этапах операции и в послеоперационном периоде, и дана оценка ее динамических изменений.

Заключение: Полученные результаты исследований позволяют рекомендовать метод модифицированной ультрафильтрации крови для коррекции нарушений водного обмена у детей при проведении операций на сердце с искусственным кровообращением. В выводах анализ данных показал, что проведение искусственного кровообращения способствует накоплению жидкости во внеклеточном внесосудистом

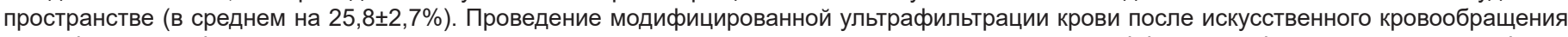
способствует профилактике накопления жидкости в экстравазальном пространстве. И у всех детей эффрект модифицированной ультрафильтрации по снижению количества воды во внеклеточном внесосудистом пространстве особенно очевиден.

Ключевые слова: модифицированная ультрафильтрация, искусственное кровообращение, биоэлектроимпеданс, общая внеклеточная вода организма, врожденные пороки сердца

\section{Введение}

Примерно с середины 90-х годов в мире начали активно изучаться эффекты модифицированной ультрафильтрации (МУФ) крови при проведении кардиохирургических операций у детей. Интересными представляются данные интраоперационной динамики общей внеклеточной воды организма (ОВВО) у детей, оперированных в условиях искусственного кровообращения (ИК) и МУФ. Методом детекции ОВВО может стать биоэлектроимпеданс (БЭИ). Впервые такая работа была выполнена в 1994 г. Maehara Т.В. и соавторами (1994). В настоящее время, активно продолжаются исследования динамики ОВВО при проведении различных видов интраоперационной ультрафильтрации (УФ) у детей. В своей работе мы проводим подобные исследования.

\section{Цель}

Исследовать динамику общей внеклеточной воды организма при проведении модифицированной ультрафильтрации после искусственного кровообращения.

\section{Материалы и методы исследования}

Общее количество пациентов находящихся под наблюдением 50. В условиях проведения МУФ крови после искусственного кровообращения изучена динамика ОВВО у 25 детей с врожденными пороками сердца (основная группа). В контрольную группу вошли дети (n=25), оперированные в условиях ИК, без проведения МУФ крови, все они находились на лечении в отделении детской кардиохирургии, Больница Г.Монастерио, г.Масса, Италия в период с 2016 по 2017 гг. Возраст больных от 1 до 8 лет. Мониторирования внеклеточной воды во время операций и в раннем послеоперационном периоде использовали специально разработанное устройство Holtain body composition analyser (Англия).

Исследования проводили в положении больного лежа на спине. Потенциальные электроды накладывали на лодыжку и на запястье одноименной стороны тела (справа или слева). Токовые электроды располагали дистальнее потенциальных на 3-5 см.

Все операции выполнялись с применением МУФ крови, по нашей схеме (Патент №2017/1037.1) представленный на Рисунке 1.

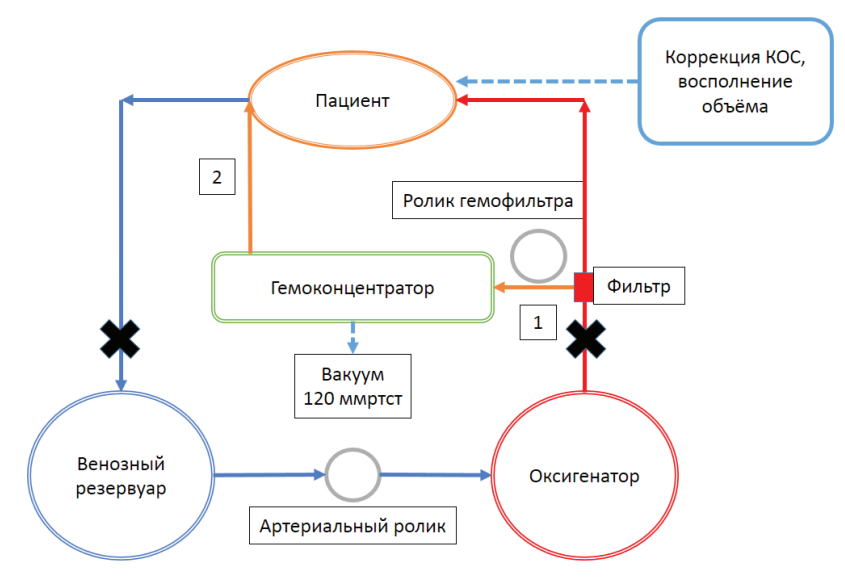

Рисунок 1 - Собственная схема проведения МУФ (Патент №2017/1037.1)

Примечание: 1 - приточная магистраль ультрафильтра, 2 отводящая магистраль ультрафильтра 
В исследовании были использованы гемоконцентраторы «Dideco» (Италия) с объемом заполнения от 50 мл, площадью фильтрующей поверхности 1,06 м и диаметром пор 65 тыс. Дальтон.

В основной и контрольной группах количество ОВВО контролировалось методом БЭИ до, во время операции и в первые двое суток в раннем послеоперационном периоде. Для удобства расчетов количество ОВВО относили к массе тела и выражали в процентах. Следует также отметить, что во всех исследуемых группах гемогидробаланс операций был вполне сопоставим и по количеству перелитых растворов во время операции (включая объем первичного заполнения ИК), и по количеству выделенной жидкости (мочи), и по объему операционной кровопотери. У пациентов в сравниваемых группах в периоперационном периоде после проведения УФ крови были выявлены изменения в динамике накопления ОВВО.

\section{Результаты}

В контрольной группе (не проводилась МУФ) динамика ОВВО у всех пациентов была однотипной, у них мы наблюдали следующие изменения:

- снижение ОВВО во время ишемии в ходе ИК;

- увеличение ОВВО в течение первых 12 часов после операции (с максимальным подъемом через 6 часов после операции);

- возвращение ОВВО к дооперационным показателям к концу вторых суток после операции.

В основной группе динамика накопления ОВВО имела

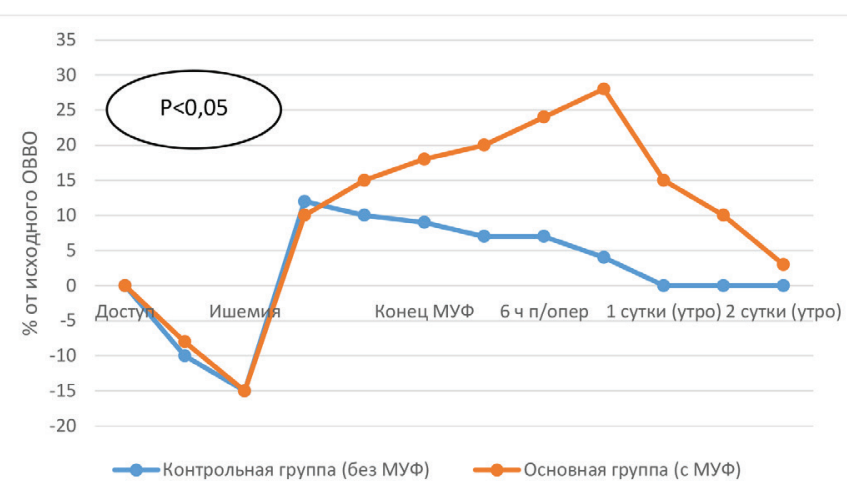

Рисунок 2 - Влияние МУФ на периоперационные изменения ОВВО в контрольной и основной группах

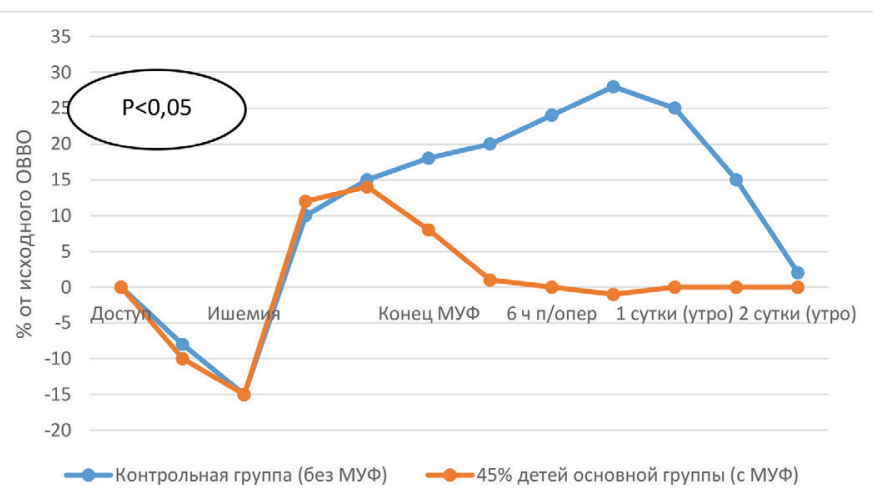

Рисунок 3 - Периоперационная динамика ОВВО у 45\% детей основной группы иной характер:

- до проведения МУФ содержание ОВВО совпадало с данными контрольной группы;

- после проведения МУФ в раннем послеоперационном периоде пик нарастания ОВВО отсутствовал;

- возвращение ОВВО после проведения МУФ к дооперационным значениям происходило достоверно раньше, чем в контрольной группе (к концу 1 суток, Рисунок 2).

Ниже приведен клинический пример, наглядно отражающий динамику гематокрита во время проведения оперативного лечения на фоне МУФ.

При детальном изучении особенностей изменения ОВВО (выраженной БЭИ) было отмечено, что у 45 \% детей основной группы после проведения МУФ ОВВО достигала дооперационного уровня и не изменялась в течении операции и раннего послеоперационного периода (Рисунок $3)$.

Этот факт, наводит на мысль, что применение МУФ кровиудетей, внекоторых случаях, позволяетконтролировать выход жидкости во внеклеточное пространство. Последнее, по-видимому, связано с возможностью удерживать величину гематокрита на приемлемых цифрах во время проведения операции [3, 4, 6, 7].

В Таблице 1 представлены цифровые значения БЭИ, определенные в исследуемых группах на разных этапах операции и в послеоперационном периоде, и дана оценка динамических изменений БЭИ в ответ на проведение МУФ.

Таблиша 1 Изменение БЭИ в контрольной и основной группах до и после проведения МУФ крови

\begin{tabular}{|c|c|c|c|c|}
\hline \begin{tabular}{|l|} 
Этапы измерения \\
БЭИ \\
\end{tabular} & \multicolumn{2}{|c|}{$\begin{array}{l}\text { Контрольная груп- } \\
\text { па, Ом }\end{array}$} & \multicolumn{2}{|c|}{ Основная группа, Ом } \\
\hline $\begin{array}{l}\text { Хирургический } \\
\text { доступ }\end{array}$ & \multicolumn{2}{|l|}{$480,5 \pm 60,5$} & \multicolumn{2}{|l|}{$513,3 \pm 72,3$} \\
\hline Начало ИК & \multicolumn{2}{|l|}{$435,7 \pm 71,3$} & \multicolumn{2}{|l|}{$497,9 \pm 54,6$} \\
\hline Ишемия миокарда & \multicolumn{2}{|l|}{$451,3 \pm 61,3$} & \multicolumn{2}{|l|}{$480,5 \pm 60,5$} \\
\hline Конец ИК & $421,8 \pm 62,6^{*}$ & \multirow[t]{4}{*}{$\mathrm{P}^{*}<0,05$} & \multicolumn{2}{|l|}{$463,1 \pm 71,3$} \\
\hline Начало МУФ & & & $442,1 \pm 71,3^{* *}$ & \multirow[t]{2}{*}{$\mathrm{P}^{*}<0,05$} \\
\hline Конец МУФ & & & $547,4 \pm 63,8^{* *}$ & \\
\hline \begin{tabular}{|l}
3 часа после \\
опералции
\end{tabular} & $391,1 \pm 70,2^{* *}$ & & \multicolumn{2}{|l|}{$545,4 \pm 71,6$} \\
\hline \multirow{2}{*}{$\begin{array}{l}6 \text { часов после } \\
\text { операции }\end{array}$} & \multicolumn{2}{|l|}{$301,4 \pm 52,3^{*}$} & \multicolumn{2}{|l|}{$512,9 \pm 51,1^{*}$} \\
\hline & \multicolumn{4}{|l|}{$\mathrm{P}^{*}<0,05$} \\
\hline \multirow{2}{*}{$\begin{array}{l}12 \text { часов после } \\
\text { операции }\end{array}$} & \multicolumn{2}{|l|}{$310,2 \pm 56,1^{*}$} & \multicolumn{2}{|l|}{$567,1 \pm 56,8^{*}$} \\
\hline & \multicolumn{4}{|l|}{$\mathrm{P}^{*}<0,05$} \\
\hline \multirow{2}{*}{$\begin{array}{l}\text { сутки после } \\
\text { операции (утро) }\end{array}$} & \multicolumn{2}{|l|}{$345 \pm 62,5^{*}$} & \multicolumn{2}{|l|}{$534,4 \pm 63,8^{*}$} \\
\hline & \multicolumn{4}{|l|}{$\mathrm{P}^{*}<0,05$} \\
\hline \multirow{2}{*}{\begin{tabular}{|l|}
1 сутки после \\
операции (вечер)
\end{tabular}} & \multicolumn{2}{|l|}{$412,8 \pm 74,5^{*}$} & \multicolumn{2}{|l|}{$523,5 \pm 51,1^{*}$} \\
\hline & \multicolumn{4}{|l|}{$\mathrm{P}^{*}<0,05$} \\
\hline \multirow{2}{*}{$\begin{array}{l}2 \text { сутки после } \\
\text { операции (утро) }\end{array}$} & \multicolumn{2}{|l|}{$503,7 \pm 56,3$} & \multirow{2}{*}{\multicolumn{2}{|c|}{$518,8 \pm 63,7$}} \\
\hline & $\mathrm{P}>0,05$ & & & \\
\hline
\end{tabular}

Примечание: $\mathrm{P} * *<0,05$ (Т- тест для зависимых выборок), $\mathrm{P} *<0,05$ (Т- тест для независимых выборок). Различия достоверны.

\section{Обсуждение}

Резюмируя вышеизложенное, можно сделать вывод, что кардиохирургические операции с ИК всегда сопровождаются нарушениями водного обмена организма, что проявляется значительным накоплением жидкости во внеклеточном пространстве, особенно в первые сутки после операции. При детальном сопоставлении данных, нами отмечены некоторые особенности накопления ОВВО у детей и взрослых. 
В частности, на примере расчета критического коэффициента повышения ОВВО показано, что у детей объем ОВВО может достигать 20,98 $\pm 2,73 \%$ и более массы тела, что, естественно, нарушает нормальное течение раннего послеоперационного периода. У взрослых объем OBВО не превышал 5,56 $\pm 2,33 \%$ от массы тела, что, повидимому, связано с эффективным функционированием мочевыделительной системы и отсутствием выраженной реакции на проведение ИК.

Изучение динамики ОВВО на фоне проведения МУФ крови, показало насколько эффективна эта процедура у пациентов, оперированных в условиях ИК. Нами отмечено, что проведение МУФ снижает количество ОВВО в раннем послеоперационном периоде. Последнее характеризуется отсутствием критического пика повышения ОВВО после окончания ИК и более ранним (к концу 1-х суток) возвращением ОВВО к дооперационным значениям. Анализ показателей импеданса тела, как величины обратной количеству ОВВО, выявил достоверное увеличение БЭИ в

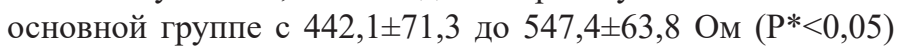
в сравнении с контролем. Кроме того, в группе больных, оперированных без МУФ крови, показатели БЭИ не только имели стабильные значения, но в ряде случаев они

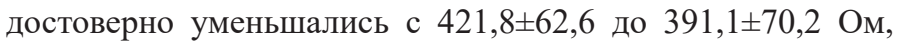
что возможно связано с более значительным накоплением OBВО у больных данной группы. Дополнительно к сказанному следует отметить, что у 45\% детей основной группы, БЭИ непосредственно после проведения МУФ крови повышался и оставался стабильным в течение всего периода наблюдения за больными. Все это позволяет высказать предположение, что МУФ крови является одним из методов профилактики и лечения экстравазальных отеков у больных, оперированных в условиях ИК. Следует отметить наибольшую эффективность МУФ крови при коррекции водного обмена у детей, оперированных в условиях ИК. Прежде всего, это объясняется особенностями ответа детского организма на гемодилюцию и гипотермию при искусственном кровообращении. Хорошо известно, что до $70 \%$ воды у детей испаряется через кожные покровы и перспирацией, и только около 30\% жидкости выводится почками. В отличие от взрослых, у которых в ответ на снижение температуры тела увеличивается фильтрационная способность почек («холодовой диурез»), у детей, наоборот, при увеличении нагрузки на клубочко-канальцевую систему, происходит снижение мочевыделения, что связано с функциональным недоразвитием у них мочевыделительной системы. Поэтому у ребенка остается единственный путь удаления жидкости - это испарение с поверхности кожи и через дыхательные пути. Во время операции возникают определенные препятствия, которые затрудняют выделение воды из организма, так как интубация трахеи приводит к разобщению легких непосредственно с воздухом, a гипотермия (чаще используемая у детей) вызывает выраженный периферический спазм сосудов кожи, тем самым, и усугубляется процесс испарения жидкости. При этом применение симпатомиметиков и диуретиков, для коррекции водных нарушений, в виду отсутствия точки приложения (недоразвитость строения клубочкоканальцевой системы почек), теряет смысл. У взрослых, наоборот, отмечено, что к моменту окончания ИК или к моменту начала ультрафильтрации диурез достигает значительного объема, и потребность в ультрафильтрации, как в методе повышающем выведение «лишней» воды, отпадает.

Полученные нами результаты и данные других исследователей $[1,2,4,5]$ позволяют рекомендовать метод МУФ крови для коррекции нарушений водного обмена у детей при проведении операций на сердце с ИК.

\section{Выводы}

Проведение искусственного кровообращения способствует накоплению жидкости во внеклеточном внесосудистом пространстве (в среднем на 25,8 $2,7 \%$ ). Данные исследований показали корреляционную зависимость между объемом жидкости внеклеточного внесосудистого пространства с одной стороны, массой тела и гематокритом во время искусственного кровообращения, с другой. Эти изменения выражены у детей гораздо больше, чем у взрослых пациентов. Проведение МУФ крови после искусственного кровообращения способствует профилактике накопления жидкости в экстравазальном пространстве. У всех детей эффект МУФ по снижению количества воды во внеклеточном внесосудистом пространстве особенно очевиден. У 45\% больных, которым проведена МУФ увеличения количества общей воды организма не наблюдалось. Небольшой подъем ОВВО у остальных приходил к норме в 1 сутки после операции, тогда как в контрольной группе лишь на вторые.

Disclosures: There is no conflict of interest for all authors.

\section{Список литературы}

1. Vladimirov Y.A., Archakov A.I. Perekisnoe okislenie lipidov v biologicheskih membranah (Lipid peroxidation in biological membranes) [in Russian]. M.: Nauka; 1972. 270 p.

2. Johnson P. Perifericheskoe krovoobrashchenie (Peripheral circulation) [in Russian]. M.: Meditsina, 1982. 440 p.

3. Nikolayenko E.M., Maslov V.A., Volkova M.I. Vyazkorezistentnye svojstva legkih i sostoyanie melkih dyhatel'nyh putej posle operacij na otkrytom serdce (Viscous-resistant lung properties and small airways condition after open heart surgery) [in Russian]. Grudnaya $i$ serdechno-sosudistaya hirurgiya. 1996;6: 294.

4. Baizhigitov N.B., Ormantayev A.K., Sepbaeva A.D., Methods of modified ultrafiltration in the surgical correction of transposition of the great arteries in newborns. Medical News of the North Caucasus. 2017;12(3):270-272 https://doi.org/10.14300/mnnc.2017.12073

5. Barst R.J, Maislin G, Fishman A.P. Vasodilator therapy in primary pulmonary hypertension in children. Circulation. 1999;99(9):11971208 .

6. Belboul A., Lofgren C., Storm C., Jungbeck M. Heparin-coated circuits reduce occult myocardial damage during CPB: A randomize, single blind clinical trial. European Journal of Cardio-Thoracic Surgery. 2000;17(5):580-587.

7. Messmer K. Introduction. In: Haemodilution. Theoretical Basis and Clinical Application. K Messer and H. Schmid-Chonbein, eds. Karger, New-York.1972; pp. 11-22.

How to cite this article: Nurlan Bayzhigitov, Vitali Pak, Tolegen Egemberdiev, Taimaz Tleuberlin. Dynamics of total extracellular water of the body during the modification of ultrafiltration after artificial circulation [in Russian]. $\mathrm{J}$ Clin Med Kaz. 2018; 3(49):42-45 